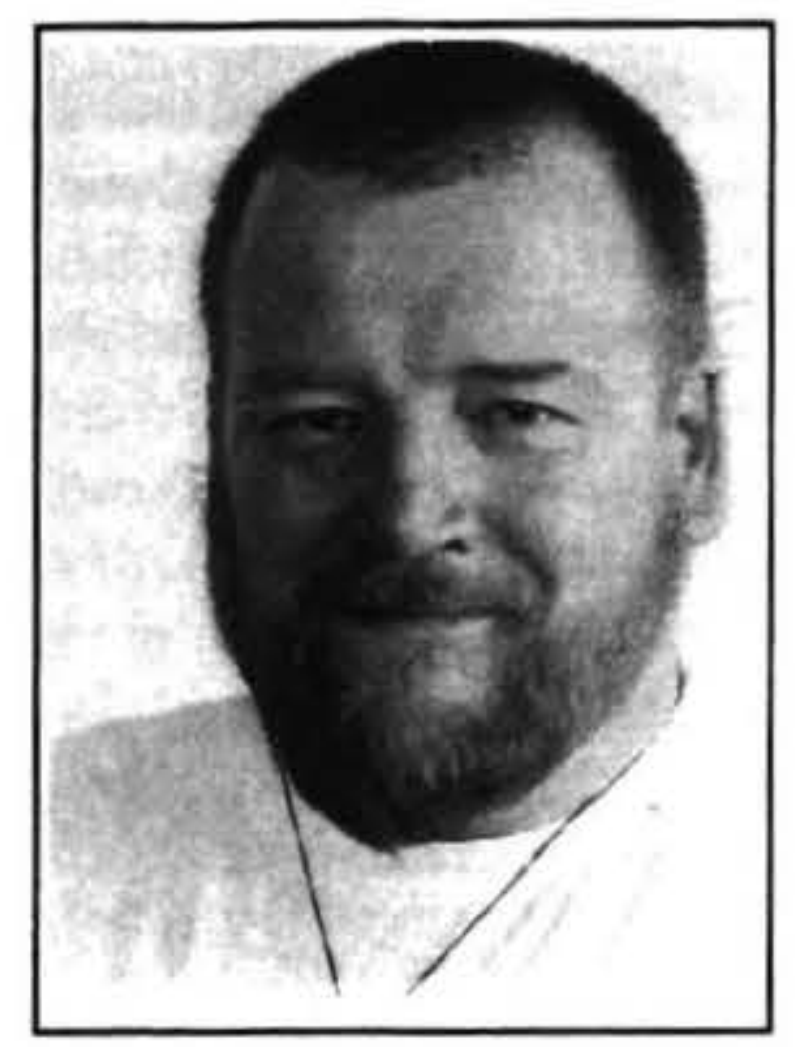

\title{
EMPLOYMENT RELATIONS IN THE NEW ZEALAND PUBLIC HEALTH SECTOR - A SURVEY
}

\author{
Michael Pye and Joanna Cullinane \\ Centre for Labour and Trade Union Studies \\ The University of Waikato
}

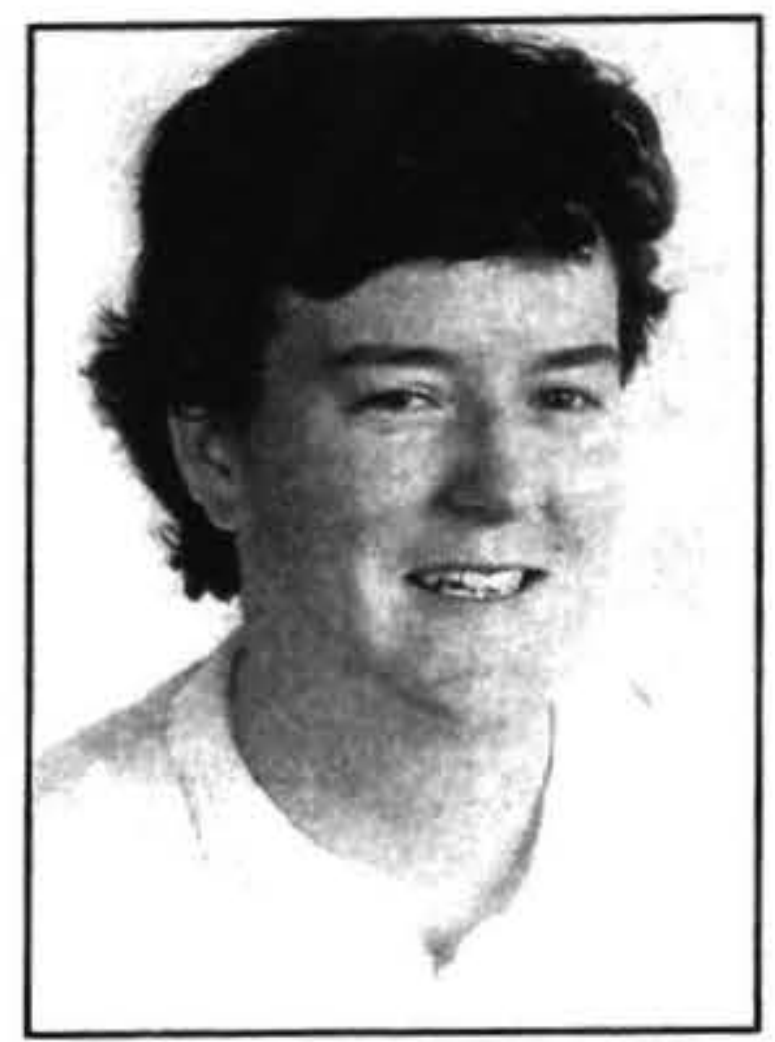

\section{Abstract}

The New Zealand Public Health sector has undergone significant political, legislative and managerial changes since 1986. These changes have had a major impact on the nature of employment relations in the sector. The unified, state sector industrial relations regime has been restructured and replaced a by diverse set of practices. Many of the changes of the last decade have had time to 'mature' and become embedded into the system and it now seems appropriate to start to identify issues that have arisen from the impact of the new regime of employment relations. This paper presents the results of a survey of related public health sector organisations including employers, unions, professional organisations, statutory bodies and funding agencies. Five distinct areas for future employment relations research, with varying levels of priority, were identified by the respondents including; 1)Workforce development and planning. 2) The nature, scope and negotiation of employment contracts. 3) The problematic of people management of largely 'professional' group of workers. 4) Relationships with external organisations such as the 'NZQA' and the 'Health and Disability Commissioner' and the impact on internal employment relations. 5) The effects of uncertainty about current health care delivery structures and possible further politically directed restructuring are having on employment relations.

This paper reports the results of a study into the research needs in the area of employment relations in the New Zealand public health sector. The study was an attempt to crystallise key research questions from the jumble of issues that face the health sector. The primary aim of the study was to provide some directions for future in-depth research, the results of which might be of some practical use to the people and organisations in the field.

This study arises in part out of a recognition that with the 'new' health reforms, there is a move away from central approaches to management. Accompanying this decentralisation of the health sector has been an inevitable fragmentation of approaches to management and in particular management of employment relations. The trend towards decentralised employment practices has been encouraged beyond the immediate health reforms themselves by other legislative changes such as the State Sector Act 1988, the Employment Contracts Act 1991, the Industry Training Act 1992, the Health and Safety in Employment Act 1992. The various non-health sector reforms have combined synergistically with the sector reforms to move the responsibility for the management of the employment relationships down from the Government and its agencies, the State Services Commission and Health Services Personal Commission, to the level of the individual enterprise.

The move towards decentralising employment relations away from the 'old' unified public service model of industrial relations in the health sector has resulted in a significant degree of diversity and fragmentation in the approaches to employment relations. This fragmentation is exacerbated by the competitive model as it is now applied in the health sector, which effectively limits co-operation between health sector enterprises despite a continuing degree of mutuality of interest in terms of achieving high quality health outcomes. To a large degree the 'new' health enterprises, the staff, their unions and professional organisations entered the new era with no organisational or sector history of anything other than the 'old' style of management, having to face serious long standing financial constraints, and with little opportunity to plan for a process of change. In the experience of one of the authors and from anecdotal reports from former colleagues (and adversaries) still practicing industrial relations in the health sector much of the period from 1988 onwards and particularly after 1991 has been a continuing series of valiant attempts to keep up with the changes. The kind of research that has tended to be done has been of the 'I need an answer to this question last week or at least by tomorrow when we go back into discussions/negotiation/ court/etc' type or descriptive, explanatory works such as those by Walsh \& Fougere (1989), Oxenbridge (1994), Cullinane (1996) and Powell (1996).

By 1996 many of the reforms have matured and despite (or because of) the current political uncertainty it is now time to undertake some prospective, future orientated research to address the employment relations questions that have arisen out of the changes.

\section{Research method}

\section{Research problem}

This research aims to develop a base of employment relations research topics in the health sector. Two research 
questions were developed:

1. what employment relations issues will impact on the health sector?; and

2. in what time frame will those issues have an impact?

(See Appendix One)

\section{Sample}

Organisations with direct roles in employment relations in the public health sector were identified as the population base for this study. The population base was divided into statutory, professional, union, and employer groups. A total of forty such organisations were identified and sampled, including the four Regional Health Authorities, 23 Crown Health Enterprises, the Ministry of Health, the State Services Commission, the Nursing Council, the College of Nurses, the College of Midwives, the New Zealand Council of Trade Unions and seven health sector unions.

\section{Methodology}

The overall purpose of the study was to develop a data base of research questions that participant organisations in the public health sector identified as needing to be addressed in the area of employment relations in the New Zealand public health sector.

The study involved asking organisations with involvement in the health sector what they thought the major issues in employment relations within the sector are, and are likely to be in the future. For the most part, these questions were posed through a written survey, but some participants voluntarily replied via telephone.The survey questions asked organisations to identify issues of employment relations that would impact on their organisation over a specific time period, and how those issues rated in terms of priority for research.

These questions were asked in an open ended manner in order avoid that tendency in most surveys to tick boxes without thought. Open ended questions were used to maximise the true expression of each organisations particular issue and as an attempt to elicit explanatory information in order to clarify these issues.

As was expected, the open ended questions posed dilemmas for some participants, this resulted in some organisations contacting the researchers to elicit further information about what was desired - a degree of uncertainty was particularly apparent about the term 'employment relations'. Follow up letters restating the research questions were sent out to nonrespondants in order to maximise the response rate. Of the 40 organisations contacted, 16 did not reply, a further five provided responses with no useable data, including one outright refusal to participate. There were nineteen responses that contained useable data giving a response rate of $47 \%$ useable replies.

\section{Data analysis}

The responses elicited were collated into a single file which was provided to three 'volunteer' analysts for coding and content analysis. The analysts selected had no connection to the health sector, this being deemed to be important to avoid a bias in the perceived themes they identified. The analysis process was carried out independently, and was somewhat 'free-form' because a majority of respondents had not followed the research instructions in terms of setting their responses to a time frame and prioritising their responses. This issue of inconsistent responses was left to the analysts to work through independently, but each arrived at similar approaches to analysing the material. The reports of the analysts were united to give the results reported in this paper based on a combined content analysis.

\section{Categories of issues identified in the content analysis}

Issues identified by the analysts from the content analysis were combined into groups of similar themes - the breakdown resulting in seven categories of issues: skills, contracts, management, change, professional and occupational structures, resources and organisational issues. These categories prove useful in amalgamating similar issues and revealing trends in concerns, but are also problematic

The skills category included such issues as training, education, the industry training organisations, the qualifications framework, occupational change affecting requisite skills, maintenance of competency, and moves to multi-skilling.

The contracts category included such issues as debate over contracts for service and of service, questions over the relative merits of individual as opposed to collective contracts, concerns over the process of negotiation, and issues relating to maintenance of flexibility in the contracting process.

The professional and occupational structures category of employment relations were concerned with issues of workforce planning, professional change, concerns over the regulation of the clinical professions, and desires for greater co-ordination in professional planning.

The management category of issues focused on the abilities of health sector management, in particular, issues of human resource management, management competency, requirements for flexibility in management and concern to improve the co-operation between management and clinical groups.

Issues of change included concern over sector wide changes, political impacts on the sector, the changes following the introduction of the Health and Disabilities Commissioner, and an overall concern that health sector problems would affect standards of care for patients and community. Other issues related to change were a desire to develop strategies of change appropriate to the sector, the changing role of unions and change to the traditional culture of the sector.

Organisational issues was the designation given to primarily enterprise level concerns such as performance/productivity, quality, remuneration, morale, job security, career development, motivation, retention of employees, desire for greater flexibility in employment, and recruitment. Although these are specific concerns, they have ties to other categories in that by-and-large they are issues exacerbated by sector wide changes. 
Among the issues of health sector resources was an overriding concern with the lack of money, and the uncertainty of future monetary resources. Also of concern in this category was issues of competition between the private and public sector affecting the traditional sharing of resources between clinicians, in particular, issues of restraint of trade and that in the current environment, it is incongruous that public resources are being used to train clinicians who will subsequently be private operators in competition with public providers.

\section{Results}

When the individual responses of the study were aggregated, the five most frequently cited issues across all respondent groups were, in order: sector change, occupational change, professional change, professional regulation, lack of resources.

Beyond simple frequency results this research has been aggregated in two ways - by comparing issues across respondent group and by combining the issues into categories with similar themes and comparing response frequency in those categories. A full set of results is included in Appendix two

\section{Employment relations issues according to respondent groups}

When the responses of individual respondents are aggregated by sample group, apparently predictable results emerge: employers are interested in remuneration, statutory groups in political influences, and occupational groups in occupational and sector change.

What does not seem to fit stereotypical concerns however, is that health sector unions are most concerned with issues of professional regulation. The stereotypical response would probably consider unions most likely to be concerned with issues of contract negotiation and remuneration - similar to those expected from employers. An explanation of this result may be in the fact that most health sector unions have a strong professional focus - unions of nurses, unions of doctors, etc. This model of unionism may extend the concerns of the unions from the immediate, and stereotypical 'pay and conditions', to a more professional strategic view. Of equal interest was the clear concern expressed by one of the 'blue collar' unions about the issue of training for their members in terms of delivering quality health outcomes.

\section{Employment relations issues compared by categories}

When all the issues of concern are grouped into similar themes or categories, the results indicate that issues of skill are considered most important for research, followed closely by concerns relating to organisational issues, those relating to change, and interest in professional and occupational structures. (See figure 1)

Issues identified as less important for research include issues of material resources, employment contracts, and the least important issue for research is the management of the health sector.

\section{Figure 1. Categories of employment rela- tions issues identified}

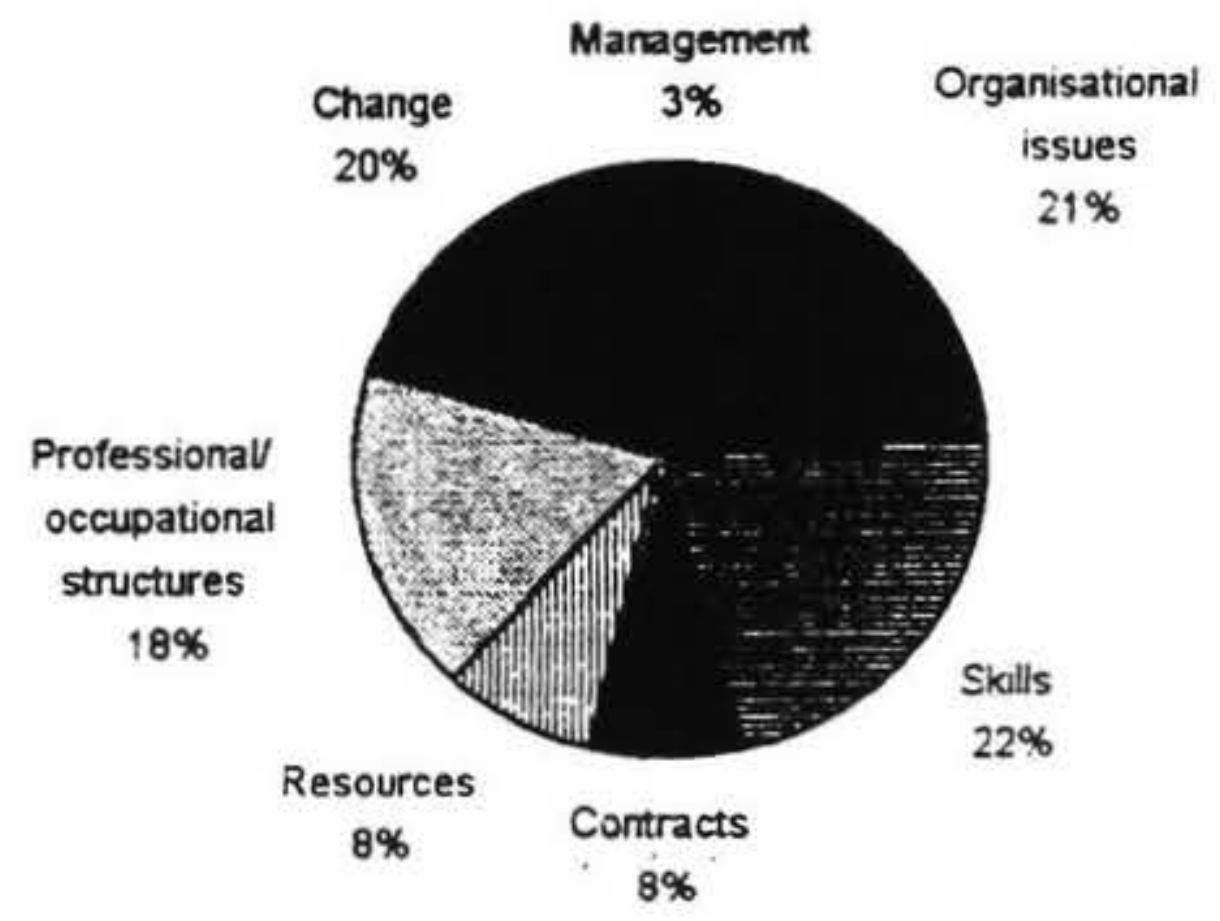

\section{Findings}

Turning the results of this survey into something useful entails going beyond the content analysis statistics, that only quantify the issues. How do the issues interrelate? Are issues cited symptoms or causes? Is research into all of the issues equally relevant? The content analysis cannot answer these questions. The results must be read in combination with the full text of responses.

\section{The nature of the results}

The open ended style questions allowed respondents to elaborate on their answers by explaining the causal relationships between the issues they identified, and wider issues that were facing the sector. One example is diagrammed in figure 2: the links between uncertain or insufficient resources, difficulties recruiting and retaining staff which was being expressed through issues of remuneration.

The issues of costs of remuneration result in organisations looking for cost savings in employment area, which leads to changes to traditional employment relationships. The employment patterns are changed to either contract out, utilise contracts for service (as opposed to contracts of service), or to institute cheaper skill mixes. These employment patterns have implications for professional structures, standards of care, professional regulation, training and development, workforce planning, and eventual skill shortages. These skill shortages bring the causal links full circle, by causing recruitment problems and inevitable remuneration issues.

Interesting comments were received from many respondents. These responses were varied, from a Crown Health Enterprise that refused to take part because they were too 


\section{Figure 2. The interrelationship of employ- ment relations issues identified}

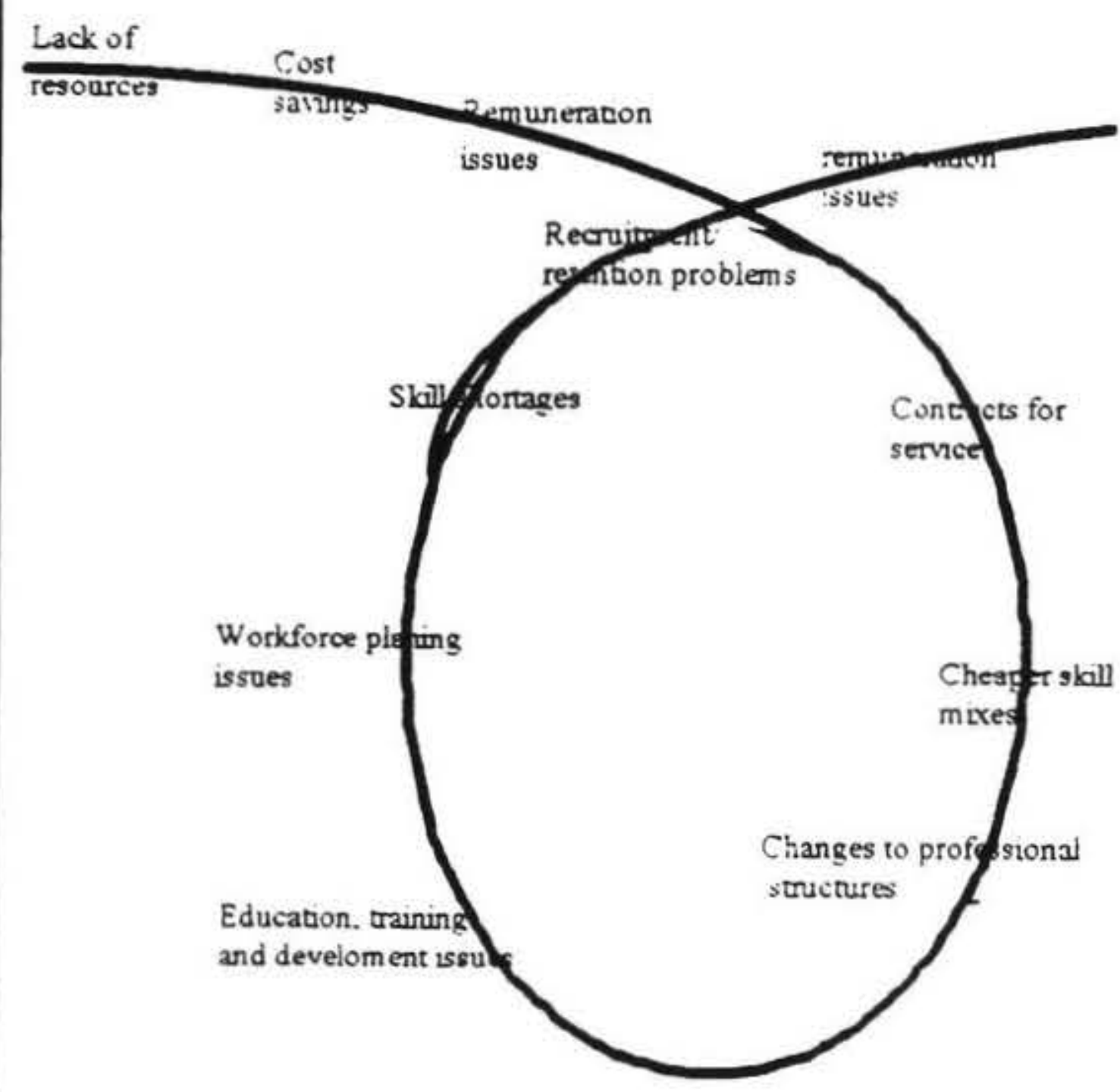

busy on their own programme of change to assist everyone else and anyway could see no value in such an exercise as this (study). Another Chief Executive categorically stated that all the answers were already known and if only health professionals "...would come to terms with the fact that others do not see their contribution as being as important or successful as they do" then things would get better. Conversely a number of organisations were clearly attempting to address very real problems in an environment that does not foster prospective research into matters of employment relations. As one of the content analysts in this project noted, there was a degree of 'panicked desperation' amongst some of the respondents; they wanted immediate assistance and were not too worried about what form this assistance took.

What research is perceived to be unnecessary? One of the conclusive points that arises out of the results, is the low interest in researching issues of management and employment contracts. This despite the fact that these areas currently capture a large degree of enterprise level attention, and a consulting base has developed around these issues. An explanation for this result may be in the immediacy of the problem: structures of management and contractual arrangements are immediate necessities in health sector operations, but not necessarily where long term research is perceived to be best focused.

What research is appropriate and necessary? The results tend to indicate that many of the issues identified as affecting employment relations in the health sector are interrelated, and also go beyond the ambit of pure industrial relations and management studies. The reforms of the health sector have changed the nature of employment relations irrevocably at all levels of the sector. This has resulted in a situation where a study of one particular component of the New Zealand health sector employment relations that does not take into account the wider political, ideological and economic factors in the wider political economy has the potential to be of limited use.

\section{Future research}

That said, it seems there are two parallel paths that might be usefully followed in future research arising out of this study. The first path would be to undertake a follow-up survey of the respondents with a more comprehensive questionnaire focussing on one or more of the key issue identified with the intent of developing a particular research project around the specific issue(s). At the same time there appears to be an opportunity for someone to undertake a large scale historical, descriptive and theoretical analysis of the development of employment relations in the health sector which might assist others in undetaking the necessary meso- and microlevel research needed to address the immediate issues in the area.

\section{References}

Cullinane, J. 1996. Employment relations at Western Bay Health. In IERA 1996: Proceedings of the 4th Annual IERA Conference. Lismore: IERA.

Oxenbridge, S. 1994. Health sector collective bargaining and the Employment Contracts Act: A case study of nurses. New Zealand Journal of Industrial Relations, 19(1), 17-33.

Powell, I. 1996. Negotiating employment contracts for senior doctors in Crown Health Enterprises: Resolving ideological divides and achieving enhancements. In J. Gibson (Ed.), Accord or Discord: The 3rd Annual IERA Conference. Sydney: IERA.

Walsh, P., \& Fougere, G. (1989). Fiscal policy, public sector management and the 1989 Health Sector strike. New Zealand Journal of Industrial Relations, 14(3), 219-229.

\section{Authors}

Michael Pye is a registered nurse and a D.Phil candidate and Joanna Cullinane is a lecturer at the Centre for Labour and Trade Union Studies at the University of Waikato, PO Box 3105, Hamilton 


\section{Appendix One: Survey Letter}

\section{Dear}

We are writing to you, as the head of one of the (employer/statutory/ professional/union) organisations which is involved in the public health sector inviting your participation in research project being currently undertaken by the Centre.

The project involves identifying current and potential future issues that need to be researched and investigated in the employment side of the health sector. In particular the research project hopes to address employment issues within the 'public' health sector. The primary objective of this project is to develop an initial database of 'research questions' which will provide a basis for future research. The ultimate outcome of the process is to provide research relevant to the people and organisations actively involved in employment relations in health sector workplaces.

We would very much like your support in this endeavour, if you are willing to have your organisation involved we would appreciate you (or some other appropriate member of your organisation) responding in as a detailed manner as possible to the following questions:
- What employment relations issues do you believe will impact on your organisation and its members in the next two years, two to five years and five to ten years, tens years on?

- Given your above response what priority on a scale of 1 (low) to 5 (high) would you give to each of those issues in terms of the need for research?

- In undertaking this project we are approaching each of the Crown Health Enterprises, the four Regional Health Authorities, the Ministry of Health and the Unions/Professional Associations representing employees in the health sector. Can you suggest any organisations or specific individuals who you feel may also be able to contribute to this project?

- Are you available for follow up contact by telephone, fax, and/or personal interview?

Thank you for your time and assistance in this project. If you have questions or comments any please do not hesitate to contact the undersigned at the Centre.

Yours sincerely

Michael Pye,

RGN, ADN, B.Soc.Sci

\section{Appendix Two. Aggregated results of content analysis of the survey responses}

$\begin{array}{lll}\text { Statutory } & \begin{array}{l}\text { Professional Unions Employers Total } \\ \text { Organisations }\end{array}\end{array}$

Skills

Training/education

ITO

NZQA

Occupational change

Competency

Multi skilling

Contracts

Professional \& occupational

Management

Resources

Organisation issues

For v. Of service

IEC $\vee$ CEC

Negotiation of

Flexibility

Workforce planning

Professional change

Competency

HRM

Filtering to private

Uncertainty
0.06

0.03

0.06

Professional regulation

Professional planning

0.03

0.03

0.03

0.03

0.03

0.03

Cooperation

0.06

Perform \& productivity

0.06

Quality \& excellence

Remuneration

Morale

Job security

Career development

Motivation

Retention

Flexibility

Recruitment

0.03

0.03

0.03

0.03

0.03

0.03

0.03

0.03

0.03

Sector

Political

0.09

HDC

Impact on patients \& communities

Union roles

Culture sect

Strategies

(a)

\begin{tabular}{|c|c|c|c|}
\hline & 0.06 & 0.05 & 0.10 \\
\hline & 0.03 & 0.02 & 0.08 \\
\hline & 0.03 & & 0.06 \\
\hline 0.2 & 0.11 & 0.02 & 0.33 \\
\hline 0.1 & 0.03 & 0.03 & 0.19 \\
\hline & 0.03 & 0.05 & 0.11 \\
\hline & 0.03 & 0.02 & 0.04 \\
\hline & & 0.05 & 0.11 \\
\hline & 0.03 & 0.02 & 0.08 \\
\hline & & 0.02 & 0.08 \\
\hline & 0.03 & 0.03 & 0.09 \\
\hline 0.1 & 0.11 & 0.05 & 0.26 \\
\hline 0.1 & 0.14 & & 0.27 \\
\hline & 0.03 & 0.03 & 0.09 \\
\hline & & 0.02 & 0.05 \\
\hline & & & 0.03 \\
\hline & & & 0.03 \\
\hline & & 0.02 & 0.02 \\
\hline 0.1 & 0.08 & 0.02 & 0.26 \\
\hline & & 0.03 & 0.03 \\
\hline & & 0.02 & 0.02 \\
\hline & 0.03 & 0.07 & 0.16 \\
\hline & & 0.02 & 0.05 \\
\hline & & 0.10 & 0.13 \\
\hline & & 0.02 & 0.05 \\
\hline & 0.06 & & 0.09 \\
\hline & & 0.03 & 0.06 \\
\hline & & 0.02 & 0.05 \\
\hline 0.1 & & 0.03 & 0.06 \\
\hline & & 0.07 & 0.10 \\
\hline 0.2 & 0.11 & 0.03 & 0.34 \\
\hline & & 0.02 & 0.11 \\
\hline 0.1 & & & 0.03 \\
\hline 0.1 & 0.06 & 0.02 & 0.17 \\
\hline & 0.03 & 0.05 & 0.08 \\
\hline & & 0.03 & 0.03 \\
\hline & & 0.03 & 0.03 \\
\hline 1 & 1 & 1 & 4.00 \\
\hline
\end{tabular}

